be a way of detecting early angina and arrhythmias after infarction and patients at high risk $^{34}$ who would benefit from surgery.

Though our study was not strictly randomised or controlled, the results show that there are differences in outcome between two different management policies: in one exercise testing, treatment with $\beta$ blockers, angiography, and coronary artery bypass grafting were used more often and this resulted in a lower mortality and morbidity. Whether the cost of these procedures justifies the results is difficult to ascertain.
1 Epstein SE, Palmeri ST, Patterson RE. Evaluation of patients after acute myocardial infarction: indications for cardiac cathererization and surgical intervention. NEngl F Med 1982;307:1487-92.

2 Theroux P, Waters DD, Halphen C, Debaisieux J-C, Mizgala HF. Prognostic value of exercise testing soon after myocardial infarction. $N \mathrm{Engl} \mathcal{F} \mathrm{Med}$ 1979;301:341-5.

3 Handler CE. Submaximal predischarge exercise testing after myocardia infarction: prognostic value and limitations. Eur Heart $\mathcal{F}$ 1985;6:510-7.

4 Krone RJ, Gillespie JA, Weld FM, Miller JP, Moss AJ, Multicenter Postinfarction Research Group. Low level exercise testing after myocardial infarction: usefulness in enhancing clinical risk stratification. Circulation 1985;71:80-9.

5 Yusuf S, Peto R, Lewis J, Collins R, Sleight P. Beta blockade during and after myocardial infarction: an overview of the randomized trials. Prog Cardiovasc Dis 1985;27:335-71.

(Accepted 27 September 1989)

\section{Parenteral antimalarial drugs: availability in acute hospitals}

\author{
Sohrab Panday, David K Raynor
}

Department of Paediatrics and Child Health, St James's University Hospital, Leeds LS9 7TF Sohrab Panday, MRCP, tutor (honorary registrar)

\section{Seacroft Hospital,} Leeds LS14 6UH

David K Raynor, MRPHARMS, senior pharmacist

Correspondence to: $\mathrm{Mr}$ Raynor.

$\operatorname{BrMed~f~1989;299:1436~}$ determine the availability of antimalarial drugs.
Availability of antimalarial drugs in hospital pharmacies in the United Kingdom, 1988

\begin{tabular}{lcc}
\hline & No $(\%)$ of hospital pharmacies \\
\cline { 2 - 3 } & Available & Not available \\
\hline Intravenous quinine & & \\
$\quad$ In stock & $245(61)$ & \\
Obtainable in under two hours & $82(20)$ & \\
Total & $327(81)$ & $75(19)$ \\
Oral quinine & $399(>99)$ & $1(<1)$ \\
Intravenous quinidine & $1(<1)$ & $399(>99)$ \\
Oral quinidine & $329(82)$ & $71(18)$ \\
Intravenous chloroquine & $193(48)$ & $207(52)$ \\
Oral chloroquine & $383(96)$ & $17(4)$ \\
\hline
\end{tabular}

the number of hospitals stocking this and other antimalarials. death that was directly attributed to the unavailability of quinine prompted Kapila et al to carry out a survey of 40 acute district hospitals in England and Wales. ${ }^{3}$ Only 10 could supply intravenous quinine. We decided to survey all hospitals in the United Kingdom to

\section{Methods and results}

All hospital pharmacies in the United Kingdom that were listed in the Chemist and Druggist Directory ${ }^{4}$ and that served patients in acute medical beds were identified. A structured questionnaire was sent to each drug information pharmacist. Of the 432 questionnaires sent, 402 (93\%) were completed and returned. The hospitals were divided into two groups: "quinine available" and "quinine unavailable."

In the first category were 327 hospitals $(81 \%)$. Of these, 245 kept a stock of the drug and a further 82 could obtain it within two hours. Roughly two fifths of the pharmacies surveyed had had to supply intravenous quinine in the previous two years. Most pharmacies obtained the drug from Macarthy's Medical Ltd (Romford, Essex).

Seventy five hospitals (19\%) were in the category "quinine unavailable." Pharmacists in 64 of these hospitals stated that intravenous quinine was not obtainable within two hours, and the remaining 11 could not say how quickly quinine could be obtained. Although the hospitals where quinine was available were in general larger than the hospitals where it was not available, in 23 hospitals with over 500 beds and 39 hospitals with between 200 and 500 beds quinine was not available.

In the United Kingdom only two regions (Northern and South Western) and two health boards (Lothian and Greater Glasgow) had a formal policy requiring that intravenous quinine was either stocked or available in an emergency. Advisory circulars were issued by the regional drug information pharmacist after Kapila et al had published their report. ${ }^{3}$ All hospitals in these regions and health boards could supply intravenous quinine within two hours. The table lists

\section{Comment}

Plasmodium falciparum infection that is resistant to treatment with chloroquine is a growing problem world wide, and because of the increase in international travel it is no longer rare in the United Kingdom. ${ }^{1}$ To avoid death in severe cases, such as in patients with cerebral malaria, the diagnosis must not be delayed and the patient should be treated immediately with intravenous quinine. ${ }^{2}$ We found a considerable improvement in the availability of intravenous quinine ( 327 of 402 hospitals) over the 1981 results (10 of 40 hospitals). ${ }^{3}$ Nevertheless, all hospita pharmacies serving patients with acute medical conditions should have intravenous quinine available at all times. $^{3}$ In our study 23 of the hospitals in which quinine was unavailable had over 500 beds. It has been suggested that intravenous quinidine is a suitable alternative, ${ }^{5}$ but this is available only on a "named patient" basis and has to be imported.

In England only two of the 14 regions had a forma policy requiring intravenous quinine to be available, and in Scotland two health boards had such a policy. These policies were shown to be fully effective. It should be possible for all pharmacies in acute hospitals to ensure intravenous quinine is available, and we propose that all regions in the United Kingdom should adopt a policy with this aim.

We thank all the pharmacists who cooperated in this study and Mrs Simone Panday for invaluable secretarial help.

1 Phillips-Howard PA, Bradley DJ, Blaze M, Hurn M. Malaria in Britain 1977-86. Br Med f 1988;296:245-8.

pred 1988;296:952.

3 Kapila M, Lee SH, Gray W, Robson A. Fatal falciparum malaria and the availability of parenteral antimalarial drugs in hospitals. $\mathrm{Br} \mathrm{Med} \mathcal{f} 1982 ; 284$ 1547-8.

4 Tutt $\mathrm{K}$, ed. Hospital pharmacists. In: The chemist and druggist directory. Tonbridge, Kent: Benn Business Information Services, 1988:E1-E14.

5 Phillips RE, Warrell DA, White NJ, Looareesuwan S, Karbwang J. Intravenous quinidine for the treatment of severe falciparum malaria. $N$ Engl 3 Med 1985;312:1273-8.

(Accepted 15 September 1989) 